\title{
Long-term results of thoracic endovascular aortic repair in atherosclerotic aneurysms involving the descending aorta
}

\author{
Martin Czerny, MD, ${ }^{a}$ Martin Funovics, MD, ${ }^{\mathrm{b}}$ Gottfried Sodeck, MD, ${ }^{\mathrm{e}}$ Julia Dumfarth, MD, ${ }^{\mathrm{c}}$ \\ Maria Schoder, MD, ${ }^{\mathrm{b}}$ Andrzej Juraszek, MS, ${ }^{\mathrm{c}}$ Tomasz Dziodzio, MS, ${ }^{\mathrm{c}}$ Daniel Zimpfer, MD, ${ }^{\mathrm{c}}$ \\ Christian Loewe, MD, ${ }^{\mathrm{b}}$ Johannes Lammer, MD, ${ }^{\mathrm{b}}$ Raphael Rosenhek, MD, ${ }^{\mathrm{d}}$ Marek Ehrlich, $\mathrm{MD},{ }^{\mathrm{c}}$ and \\ Michael Grimm, $\mathrm{MD}^{\mathrm{c}}$
}

Objective: This study evaluated long-term results of thoracic endovascular aortic repair for atherosclerotic aneurysms involving descending aorta.

\begin{abstract}
Methods: One hundred thirteen patients underwent thoracic endovascular aortic repair for this indication from 1996 to 2009. Mean follow-up was $54 \pm 38$ months (5-144 months). In-hospital mortality, neurologic injury, need for rerouting, occurrence of endoleaks and their treatment, and survival were recorded.
\end{abstract}

\begin{abstract}
Results: In-hospital mortality was $5.3 \%$. Transient neurologic injury rate was $2.6 \%$. Previous rerouting was performed in $51 \%$. Assisted early and late type I and III endoleak rates were $7.9 \%$ and $5.7 \%$, respectively. Five percent of patients required late surgical conversion. Actuarial survivals were $86 \%, 60 \%$, and $42 \%$ at 1 , 5 , and 10 years, respectively. Aorta-related actuarial survivals were $94 \%, 90 \%$, and $83 \%$ at 1,5 , and 10 years, respectively. Cox regression analysis revealed higher number of prostheses as independent risk factor for early (hazard ratio, 5.38; 95\% confidence interval, 1.68-42.37) and late (hazard ratio, 8.49; 95\% confidence interval, 1.09-66.06) endoleak formation. Female sex (hazard ratio, 0.35; 95\% confidence interval, 0.13-0.99), no arch involvement (hazard ratio, $0.21 ; 95 \%$ confidence interval, $0.05-0.08$ ), and higher number of prostheses (hazard ratio, $7.95 ; 95 \%$ confidence interval, $1.36-46.58$ ) affected survival.
\end{abstract}

Conclusions: Aorta-related survival is excellent among patients undergoing thoracic endovascular aortic repair for atherosclerotic aneurysms involving the descending aorta. Life-long surveillance remains mandatory, with early and late failure uncommon but still needing consideration. Thoracic endovascular aortic repair in this group of patients remains attractive and has now proven durability. (J Thorac Cardiovasc Surg 2010;140:S179-84)

Thoracic endovascular aortic repair (TEVAR) has changed attitudes toward treating thoracic aortic disease and has broadened options for patients with acute and chronic thoracic aortic pathologies. ${ }^{1-7}$ This has led to a multiplicity of reports on feasibility as well as on short-term and midterm results regarding durability. ${ }^{8-11}$ No data are available, however, regarding long-term results of this treatment modality. Such data are strongly needed to discover the mechanisms of both success and failure, to provide recommendations regarding potential broader implementation of the technique, and to put the technique into perspective. This study evaluated longterm results of TEVAR for atherosclerotic aneurysms involving the descending aorta.

\footnotetext{
From the Department of Cardiovascular Surgery, ${ }^{\text {a }}$ University Hospital Berne, Berne, Switzerland; the Departments of Interventional Radiology, ${ }^{\mathrm{b}}$ Cardiac Surgery, ${ }^{\mathrm{c}}$ and Cardiology, ${ }^{\mathrm{d}}$ Medical University of Vienna, Vienna, Austria; and the Department of Cardiology, ${ }^{e}$ Krankenanstalt Rudolfstiftung, Vienna, Austria.

Disclosures: Martin Czerny, Martin Funovics, Gottfried Sodeck, ulia Dumfarth, Maria Schoder, Andrzej Juraszek, Tomasz Dziodzio, Daniel Zimpfer, Christian Loewe, Johannes Lammer, Raphael Rosenhek, Marek Ehrlich, and Michael Grimm have nothing to disclose with regard to commercial support.

Received for publication April 27, 2010; revisions received May 31, 2010; accepted for publication June 21, 2010.

Address for reprints: Michael Grimm, MD, Waehringer Guertel 18-20, A-1090

Vienna, Austria (E-mail: michael.grimm@meduniwien.ac.at).

$0022-5223 / \$ 36.00$

Copyright $\subset 2010$ by The American Association for Thoracic Surgery

doi:10.1016/j.jtcvs.2010.06.031
}

\section{MATERIALS AND METHODS}

Between 1996 and 2009, a total of 274 patients underwent TEVAR for acute and chronic aortic disease in our department. One hundred thirteen consecutive patients underwent TEVAR for atherosclerotic aneurysms involving the descending aorta. No patients with diagnosed or suspected connective tissue disorders were included in this series because we considered such disorders to be a contraindication to TEVAR, except for bail-out procedures. Demographic characteristics and clinical risk factors are shown in Table 1. Surgical access was gained through the common femoral artery in $63 \%$ of cases. In the remaining patients, alternate access sites were chosen (common iliac artery $35 \%$ and infrarenal aorta $2 \%$ ). The institutional review board approved the study and waived the need for patient consent.

\section{Data Collection and Follow-up Protocol}

Data were prospectively collected. Patients were subjected to a strict follow-up protocol that required a contrast spiral computed tomographic scan and both clinical and laboratory evaluations at 3, 6, and 12 months after TEVAR and then annually thereafter. Endoleaks were defined according to reporting standards. ${ }^{12,13}$

\section{Operative Procedure and Stent-Graft Systems Used}

Preoperative rerouting procedures were performed to achieve a sufficient proximal or distal landing zone of at least $2 \mathrm{~cm}$. Procedures were performed metachronously, with an interval of 1 week between rerouting and TEVAR. Seven different commercially available stent-graft systems were used. The types of stent-grafts and the frequencies of their use are depicted in Table 2. 


\section{Abbreviations and Acronyms \\ $\mathrm{CI} \quad=$ confidence interval \\ $\mathrm{HR}=$ hazard ratio \\ TEVAR $=$ thoracic endovascular aortic repair}

\begin{abstract}
Statistical Analysis
Continuous data are presented as the median and interquartile range (range from the 25th to the 75th percentiles). Discrete data are given as counts and percentages. Comparisons of continuous data were performed by Mann-Whitney U tests, and groups of categoric data were compared by $\chi^{2}$ tests. Spearman test was applied for correlations. Kaplan-Meier statistics were used to calculate survivals and freedoms from valve-related complications, and the log-rank test was used to determine intergroup differences. Finally, we used multivariate Cox regression analysis to identify independent predictors of early and late endoleaks and of survival. Regression diagnostics and overall model fit were determined according to standard procedures. Calculations were performed with SPSS for Mac OsX (version 16.0; SPSS Inc, an IBM Company, Chicago, Ill).
\end{abstract}

\section{RESULTS}

\section{In-Hospital Mortality and Neurologic Injury}

Overall in-hospital mortality was $5.3 \%$. Mortality among elective patients was $4.0 \%$, whereas mortality among emergency patients was $15.3 \%$. Transient neurologic injury could be observed in $2.6 \%$. Symptomatic spinal cord injury was not observed in this series.

\section{Need For Rerouting Procedures and Extent of Aneurysms}

Previous rerouting procedures were necessary in $51 \%$. Table 3 depicts types and numbers. Tables 4 and 5 depict origins and extents of aneurysms.

\section{Early Type I and III Endoleaks and Need for Reinterventions}

Early type I and III endoleaks were observed in $25.6 \%$. Assisted early endoleak rate was $7.9 \%$. The remaining endoleaks required a watchful waiting strategy. Among those with an observational approach, 2 patients underwent late surgical conversion.

\section{Early Type II Endoleaks and Need for Reinterventions}

Early type II endoleaks were observed in $4.4 \%$. In $3.5 \%$, an increase of maximum aneurysm diameter could be observed. Two patients eventually had to undergo late surgical conversion because of a lack of other options.

\section{Late Type I and III Endoleaks and Need for Reinterventions}

Late type I or III endoleaks occurred in $11.5 \%$. Among affected patients, $46 \%$ were treated with reoperative TE-
TABLE 1. Demographic characteristics and clinical risk factors

\begin{tabular}{lc}
\hline Age (y, median and interquartile range) & $73(67-77)$ \\
Female (\%) & $30 \%$ \\
Mean aneurysm diameter (cm, median and & $6.6(6.0-7.2)$ \\
$\quad$ interquartile range) & \\
Proximal landing zone (cm, median and interquartile range) & $3.0(2.0-5.0)$ \\
Distal landing zone (cm, median and interquartile range) & $5.0(3.0-5.0)$ \\
Suitable for conventional surgery (\%) & $16 \%$ \\
Additive EuroSCORE (median and interquartile range) & $9(7-11)$ \\
Logistic EuroSCORE (median and interquartile range) & $15(10-28)$ \\
Chronic obstructive pulmonary disease (\%) & $50 \%$ \\
Coronary artery disease (\%) & $31 \%$ \\
Previous infrarenal aortic replacement (\%) & $12 \%$ \\
Renal insufficiency (\%) & $11 \%$ \\
Diabetes mellitus (\%) & $8 \%$ \\
Previous ascending aortic replacement $(\%)$ & $6 \%$ \\
Previous coronary artery bypass grafting $(\%)$ & $5 \%$ \\
\hline
\end{tabular}

VAR, $46 \%$ had to be observed, and $8 \%$ had to undergo late surgical conversion.

\section{Endotension and Need for Reinterventions}

Endotension was observed in 2 patients. Both patients underwent successful reoperative TEVAR.

\section{Survival and Aorta-Related Survival}

The mean follow-up period was $54 \pm 38$ months (range, 5-144 months). Overall actuarial survivals were $86 \%, 60 \%$, and $42 \%$ at 1,5 , and 10 years, respectively (Figure 1). Aorta-related actuarial survivals were $94 \%, 90 \%$, and $83 \%$ at 1,5 , and 10 years, respectively (Figure 2 ).

\section{Cox Regression Analysis}

Early endoleak formation (Table 6). A higher number of prostheses used (hazard ratio [HR], 5.38; 95\% confidence interval [CI], 1.68-42.37) turned out to be the only independent risk factor for early endoleak formation. Involvement of the aortic arch (HR, $0.41 ; 95 \%$ CI, 0.11-1.57) and an earlier year of TEVAR (HR, 0.58; 95\% CI, 0.14-2.51) did not show any influence on early endoleak formation.

Late endoleak formation (Table 7). A higher number of prostheses used also turned out to be the only independent predictor of late endoleak formation (HR, 8.49, 95\% CI

TABLE 2. Types of stent-grafts used

\begin{tabular}{lc}
\hline & No. \\
\hline Gore Excluder & $27 \%$ \\
Medtronic Talent & $20 \%$ \\
Gore TAG & $19 \%$ \\
Bolton Relay & $16 \%$ \\
Medtronic Valiant & $14 \%$ \\
Endomed & $3 \%$ \\
Jotec Evita & $1 \%$ \\
\hline
\end{tabular}


TABLE 3. Types of rerouting procedures performed

\begin{tabular}{lr}
\hline Subclavian transposition & $30 \%$ \\
Double transposition & $42 \%$ \\
Entire arch transposition & $23 \%$ \\
Other arch rerouting procedures & $5 \%$ \\
\hline
\end{tabular}

1.09-66.06). Neither involvement of the aortic arch (HR, 0.32 ; 95\% CI, 0.09-1.09) nor an earlier year of TEVAR (HR, 2.15; 95\% CI, 0.72-6.46) showed any influence on early endoleak formation.

Survival (Table 8). Female sex turned out to be an independent predictor of survival (HR, 0.35; 95\% CI, 0.13-0.99). Furthermore, lack of arch involvement (HR, 0.21; 95\% CI, $0.05-0.08)$ as well as a higher number of prostheses used independently affected survival (HR, 7.95; 95\% CI, 1.3646.58).

\section{DISCUSSION}

In-hospital mortality was pleasantly low among elective patients, underlining the limited physiologic burden of the procedure. Among emergency patients, mortality was higher as expected, most likely because inflammation, hemodynamic compromise, and resulting problems of the acute state, such as renal failure, are limiting. ${ }^{14}$ We observed a very low incidence of central neurologic injury, with 4 clinically regressive left-sided lesions. This finding is important, because it confirms our policy of routine subclaviancarotid transposition in each elective case to preserve left posterior cerebellar circulation and thereby also maintain spinal cord perfusion, with events occurring exclusively in patients with impaired left subclavian perfusion. ${ }^{15}$ With respect to cerebrospinal fluid drainage, we do follow a distinct strategy, which has been described in detail previously. ${ }^{16}$ Cerebrospinal fluid drainage was not routinely applied because of the necessity of maintaining continuing antiplatelet therapy related to severe cardiovascular comorbidities in many patients. Because of our previous experience with high-risk patients, we concluded that extensive stent-graft coverage of the entire thoracic aorta can be performed safely in most patients when 3 of 4 spinal cordsupplying vascular territories are preserved. ${ }^{16}$

Furthermore, the issue of suitability for conventional surgery warrants discussion, because this remains a subjective decision of the individual treating physician. Even now, there is occasional dissent within our group regarding this

TABLE 4. Origin of aneurysms (according to frequency)

\begin{tabular}{lr}
\hline Proximal third of descending aorta & $48 \%$ \\
Distal aortic arch & $22 \%$ \\
Mid third of descending aorta & $17 \%$ \\
Proximal aortic arch & $6 \%$ \\
Mid aortic arch & $5 \%$ \\
Distal third of descending aorta & $2 \%$ \\
\hline
\end{tabular}

TABLE 5. Extent of aneurysms (according to frequency)

\begin{tabular}{ll}
\hline Thoracoabdominal transition & $29 \%$ \\
Below thoracoabdominal transition & $23 \%$ \\
Distal third of descending aorta & $23 \%$ \\
Proximal third of descending aorta & $13 \%$ \\
Mid third of descending aorta & $12 \%$ \\
\hline
\end{tabular}

decision. Summarizing, multisegmental thoracic aortic disease, which reflects a higher disease burden, is grounds for unsuitability in combination with at least 1 of the following factors: need for previous or recurring cardiac surgery before aortic surgery, active malignancy, chronic obstructive pulmonary disease with a forced expiratory volume in 1 second less than 11, and frailty, which has no clear definition in this setting and therefore remains subjective. Nevertheless, the underlying aortic disease has to be the limiting factor for the life expectancy in such cases. Otherwise, we would treat computed tomographic scans and not patients.

Previous work has shown that the length of the landing zone is among the most important independent predictors of early and late endoleak formation. ${ }^{17,18}$ Stimulated by this finding, we have further expanded our policy of creating sufficient landing zones. We were thus able to eliminate the length of the landing zone as an independent risk factor for endoleak formation. Recent work has also confirmed that the fact of arch rerouting per se does not increase cumulative risk. ${ }^{19}$ It might be of further interest to note that more than half of all patients required transpositions to create sufficient landing zones, underlining the finding that the simple, unisegmental atherosclerotic descending aortic aneurysm is the exception, not the rule.

Assisted primary endoleak rate was acceptably low not only with endoleak treatment but also with a tailored watchful waiting strategy. It is a matter of speculation which endoleaks may resolve spontaneously and which should be treated immediately. Nevertheless, physicians should be aware that a huge (and especially proximal) type I endoleak aggravates the natural course of the underlying disease, because blood pressure in the blind sac may be substantially higher than that in downstream aortic segments. Early type III endoleaks mostly result from insufficient overlapping zones, as well as from disregarding anatomy, especially steep angles at the thoracoabdominal transition, and should be avoidable in most cases today. ${ }^{17,18}$

Interestingly, the percentage of type II endoleaks requiring treatment was high. This is in contrast to previous findings, not only for TEVAR but also for endovascular aortic repair in general. To our impression, the segment as well as the source of retrograde filling of the aneurysmal sac is of importance. Both conversions to open surgery started with retrograde filling of the aneurysmal sac from an overstated left subclavian artery. For surgical conversion, an enlargement of not only the sac but also the proximal neck needed to be observed. In fact, in TEVAR as well as 


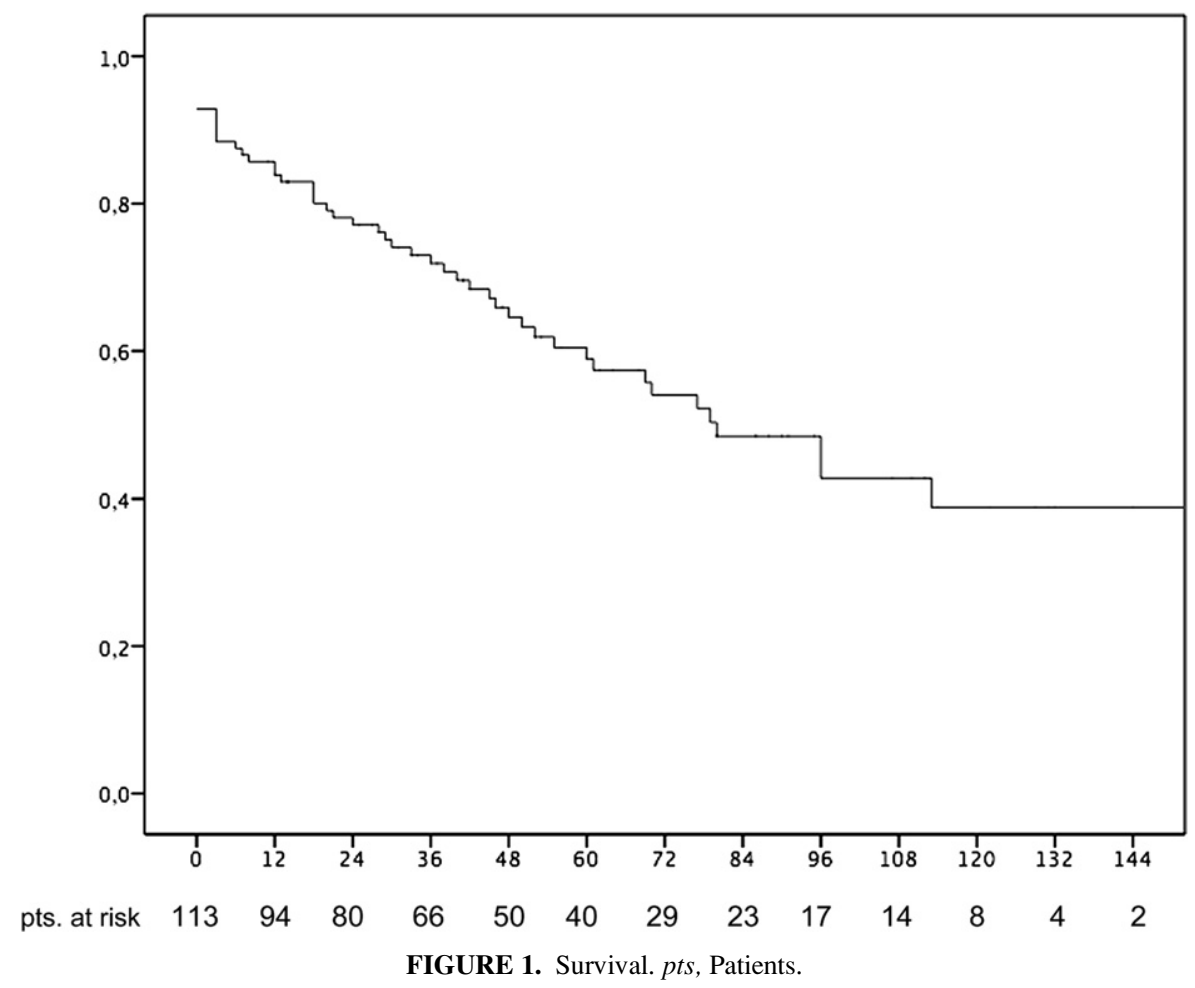

endovascular aortic repair in general, isolated small intercostal arteries have no significant effect in time. ${ }^{17,20}$

Previous work from our group suggested that early endoleak formation is not associated with late endoleak forma- tion. ${ }^{17}$ This is confirmed by this analysis, because no patient with a successfully treated early endoleak showed a late endoleak with the same cause. This finding does, however, underline the necessity for lifelong surveillance,

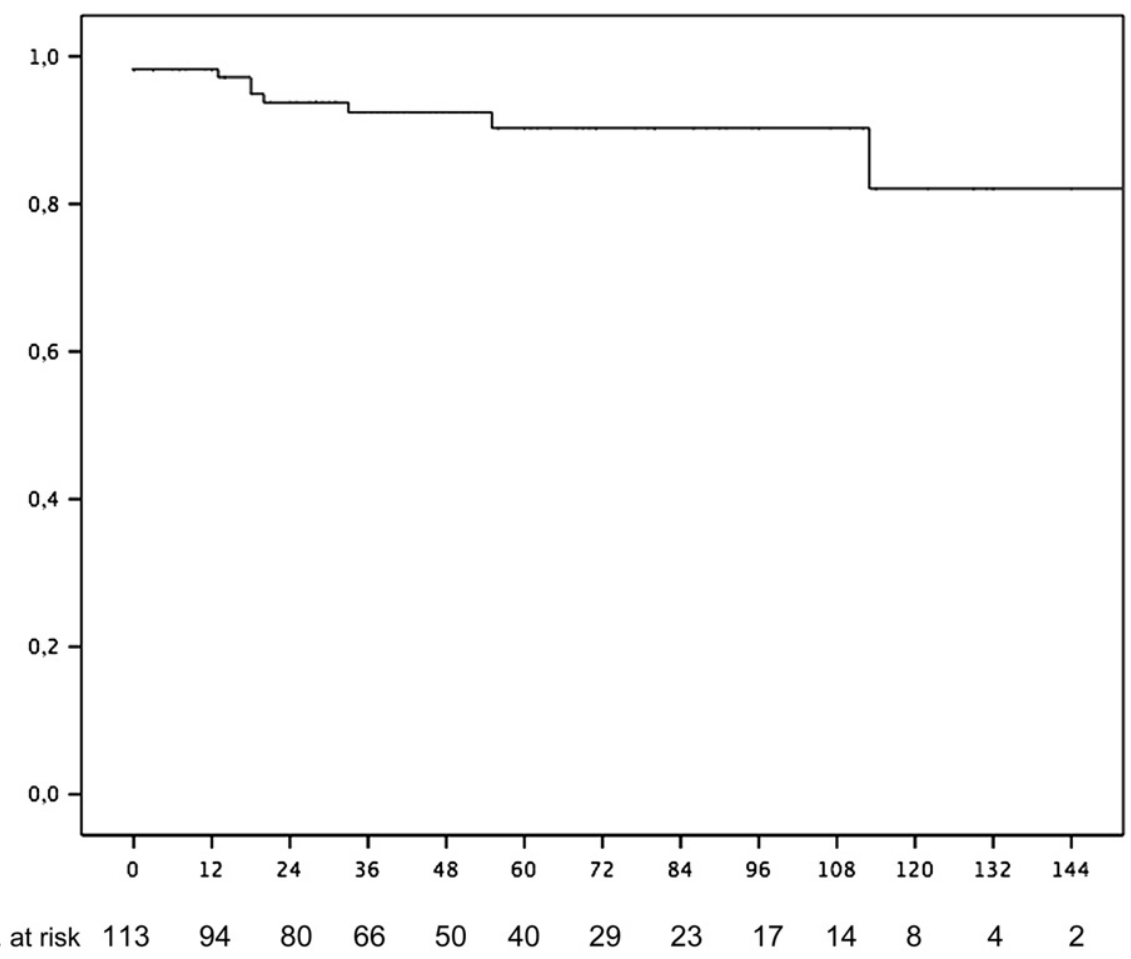

FIGURE 2. Aorta-related survival. pts, Patients. 
TABLE 6. Cox proportional hazards model: Early endoleak formation

\begin{tabular}{lcc}
\hline \multicolumn{1}{c}{ Variable } & $\begin{array}{c}\text { Hazard } \\
\text { ratio }\end{array}$ & $\begin{array}{c}\mathbf{9 5 \%} \text { Confidence } \\
\text { interval }\end{array}$ \\
\hline Age $>75$ y & 0.45 & $0.15-1.36$ \\
Female sex & 1.31 & $0.45-3.80$ \\
Operative year after 2001 & 0.58 & $0.14-2.51$ \\
Emergency & 2.19 & $0.14-2.51$ \\
Arch involvement & 0.41 & $0.11-1.57$ \\
Proximal landing zone (cm) & 0.76 & $0.48-1.20$ \\
No. of prostheses used (higher) & 5.38 & $0.68-42.37$ \\
\hline
\end{tabular}

because late endoleaks or aortic pathology in different segments requiring treatment may develop in time, such as type $\mathrm{V}$ endoleaks that should no longer be seen with recent technology. ${ }^{21}$

Early endoleak formation, like late endoleak formation, was independently predicted by a higher number of prostheses used. This finding seems likely to be reproducible, because a higher number of prostheses may decrease lateral stability, especially in angulated anatomy, and may thereby predispose toward early and late failure. ${ }^{17}$ In consequence, the industry now provides physicians with prostheses as long as $250 \mathrm{~mm}$, which may well serve to solve this problem.

Aorta-related survival, which should be regarded as among the strongest parameters of success or failure of any aortic therapy, was excellent. Survival itself was independently predicted by female sex, a higher number of prostheses, and the fact that the aortic arch was not involved in the aneurysm. Women had a similar age distribution to men in this series, which may help to explain this finding. Additionally, the incidences of both coronary artery disease and peripheral arterial occlusive disease were lower among women. A higher number of prostheses predicted adverse outcome, perhaps because prosthesis number reflects the multisegmental nature of the disease and is thereby directly related to the disease burden. The fact that noninvolvement of the arch turned out to favorably influence survival may be related to the same underlying cause.

In summary, aorta-related survival is excellent among patients undergoing TEVAR for atherosclerotic aneurysms involving the descending aorta. Lifelong surveillance re-

TABLE 7. Cox proportional hazards model: Late endoleak formation

\begin{tabular}{lcc}
\hline \multicolumn{1}{c}{ Variable } & $\begin{array}{c}\text { Hazard } \\
\text { ratio }\end{array}$ & $\begin{array}{c}\mathbf{9 5 \%} \text { Confidence } \\
\text { interval }\end{array}$ \\
\hline Age $>75$ y & 2.03 & $0.84-4.91$ \\
Female sex & 0.49 & $0.18-1.32$ \\
Operative year after 2001 & 2.15 & $0.72-6.46$ \\
Emergency & 0.49 & $0.10-2.31$ \\
Arch involvement & 0.32 & $0.09-1.09$ \\
Proximal landing zone (cm) & 0.64 & $0.33-1.26$ \\
No. of prostheses used (higher) & 8.49 & $1.09-66.06$ \\
\hline
\end{tabular}

TABLE 8. Cox proportional hazards model: Survival

\begin{tabular}{lcc}
\hline \multicolumn{1}{c}{ Variable } & $\begin{array}{c}\text { Hazard } \\
\text { ratio }\end{array}$ & $\begin{array}{c}\mathbf{9 5 \%} \text { Confidence } \\
\text { interval }\end{array}$ \\
\hline Age $>75$ y & 2.03 & $0.84-4.91$ \\
Female sex & 0.35 & $0.13-0.99$ \\
Suitable for open repair & 0.38 & $0.07-2.15$ \\
Operative year after 2001 & 0.82 & $0.27-2.50$ \\
Emergency & 0.71 & $0.13-3.99$ \\
No arch involvement & 0.21 & $0.05-0.08$ \\
No. of prostheses used (higher) & 7.95 & $1.36-46.58$ \\
Early endoleak formation & 0.50 & $0.12-2.13$ \\
Late endoleak formation & 0.61 & $0.17-2.14$ \\
Surgical conversion & 1.78 & $0.17-19.13$ \\
\hline
\end{tabular}

mains mandatory, because early and late failure-although not common-must still be considered. TEVAR in this group of patients remains attractive and now has proven durability.

\section{References}

1. Cambria RP, Crawford RS, Cho JS, Bavaria J, Farber M, Lee WA, et al. A multicenter clinical trial of endovascular stent graft repair of acute catastrophes of the descending thoracic aorta. J Vasc Surg. 2009;50:1255-64.

2. Szeto WY, McGarvey M, Pochettino A, Moser GW, Hoboken A, Cornelius K, et al. Results of a new surgical paradigm: endovascular repair for acute complicated type B aortic dissection. Ann Thorac Surg. 2008;86:87-93.

3. Grimm M, Loewe C, Gottardi R, Funovics M, Zimpfer D, Rodler S, et al. Novel insights into the mechanisms and treatment of intramural hematoma affecting the entire thoracic aorta. Ann Thorac Surg. 2008;86:453-6.

4. Czerny M, Zimpfer D, Rodler S, Funovics M, Dorfmeister M, Schoder M, et al. Endovascular stent-graft placement of aneurysms involving the descending aorta originating from chronic type B dissections. Ann Thorac Surg. 2007;83: 1635-9.

5. Nienaber CA, Rousseau H, Eggebrecht H, Kische S, Fattori R, Rehders TC, et al Randomized comparison of strategies for type B aortic dissection: the INvestigation of STEnt Grafts in Aortic Dissection (INSTEAD) trial. Circulation. 2009; 120:2519-28.

6. Gottardi R, Zimpfer D, Funovics M, Schoder M, Lammer J, Wolner E, et al. Mid-term results after endovascular stent-graft placement due to penetrating atherosclerotic ulcers of the thoracic aorta. Eur J Cardiothorac Surg. 2008;33: 1019-24.

7. Stampfl P, Greitbauer M, Zimpfer D, Fleck T, Schoder M, Lammer J, et al. Midterm results of conservative, conventional and endovascular treatment for acute traumatic aortic lesions. Eur J Vasc Endovasc Surg. 2006;31:475-80.

8. Zimpfer D, Czerny M, Kettenbach J, Schoder M, Wolner E, Lammer J, et al. Treatment of acute type a dissection by percutaneous endovascular stent-graft placement. Ann Thorac Surg. 2006;82:747-9.

9. Dambrin C, Marcheix B, Hollington L, Rousseau H. Surgical treatment of an aortic arch aneurysm without cardio-pulmonary bypass: endovascular stent-grafting after extra-anatomic bypass of supra-aortic vessels. Eur J Cardiothorac Surg. 2005;27:159-61.

10. Makaroun MS, Dillavou ED, Wheatley GH, Cambria RP, Gore TAG Investigators. Five-year results of endovascular treatment with the Gore TAG device compared with open repair of thoracic aortic aneurysms. J Vasc Surg. 2008; 47:912-8.

11. Fattori R, Nienaber CA, Rousseau H, Beregi JP, Heijmen R, Grabenwöger M, et al. Results of endovascular repair of the thoracic aorta with the Talent Thoracic stent graft: the Talent Thoracic Retrospective Registry. J Thorac Cardiovasc Surg. 2006;132:332-9.

12. Chaikof EL, Blankensteijn JD, Harris PL, White GH, Zarins CK, Bernhard VM et al. Reporting standards for endovascular aortic aneurysm repair. $J$ Vasc Surg. 2005;35:1048-60.

13. Turina MI, Shennib H, Dunning J, Cheng D, Martin J, Muneretto C, et al. EACTS/ ESCVS best practice guidelines for reporting treatment results in the thoracic aorta. Eur J Cardiothorac Surg. 2009;35:927-30. 
14. Wang GJ, Fairman RM, Jackson BM, Szeto WY, Pochettino A, Woo EY. The outcome of thoracic endovascular aortic repair (TEVAR) in patients with renal insufficiency. J Vasc Surg. 2009;49:42-6.

15. Cooper DG, Walsh SR, Sadat U, Noorani A, Hayes PD, Boyle JR. Neurological complications after left subclavian artery coverage during thoracic endovascular aortic repair: a systematic review and meta-analysis. J Vasc Surg. 2009;49: 1594-601.

16. Gottardi R, Dumfarth J, Holfeld J, Schoder M, Funovics M, Laufer G, et al. Symptomatic spinal cord malperfusion after stent-graft coverage of the entire descending aorta. Eur J Cardiothorac Surg. 2010;37:1081-5.

17. Czerny M, Grimm M, Zimpfer D, Rodler S, Gottardi R, Hutschala D, et al. Results after endovascular stent graft placement in atherosclerotic aneurysms involving the descending aorta. Ann Thorac Surg. 2007;83:450-5.
18. Czerny M, Cejna M, Hutschala D, Fleck T, Holzenbein T, Schoder M, et al. Stentgraft placement in atherosclerotic descending thoracic aortic aneurysms: midterm results. J Endovasc Ther. 2004;11:26-32.

19. Gottardi R, Funovics M, Eggers N, Hirner A, Dorfmeister M, Holfeld J, et al. Supra-aortic transposition for combined vascular and endovascular repair of aortic arch pathology. Ann Thorac Surg. 2008;86:1524-9.

20. Teufelsbauer H, Prusa AM, Wolff K, Polterauer P, Nanobashvili J, Prager M, et al. Endovascular stent grafting versus open surgical operation in patients with infrarenal aortic aneurysms: a propensity score-adjusted analysis. Circulation. 2002;106:782-7.

21. Zimpfer D, Schoder M, Gottardi R, Lammer J, Wolner E, Grimm M, et al. Treatment of type $\mathrm{V}$ endoleaks by endovascular redo stent-graft placement. Ann Thorac Surg. 2007;83:664-6. 